\title{
ARTIGO
}

do https://doi.org/10.22481/praxisedu.v16i41.6268

\section{DO DETERMINISMO CONTEUDISTA À RECONFIGURAÇÃO METODOLÓGICA E INSTRUMENTAL: UMA EXPERIÊNCIA COM O MOBILE LEARNING NO CURSO PROFUNCIONÁRIO}

\author{
FROM CONTEUDIST DETERMINISM TO METHODOLOGICAL AND \\ INSTRUMENTAL RECONFIGURATION: AN EXPERIENCE WITH MOBILE \\ LEARNING IN THE PROFUNCIONÁRIO COURSE
}

\begin{abstract}
DEL DETERMINISMO CONTEUDISTA A LA RECONFIGURACION METODOLÓGICA E INSTRUMENTAL: UNA EXPERIENCIA CON APRENDIZAJE MÓVIL EN EL CURSO PROFUNCIONÁRIO
\end{abstract}

\author{
Belmiro Marcos Beloni \\ Universidade Tecnológica Federal do Paraná - Brasil \\ Secretaria de Estado da Educação do Paraná - Brasil
}

Alessandra Dutra

Universidade Tecnológica Federal do Paraná - Brasil

André Luis Trevisan

Universidade Tecnológica Federal do Paraná - Brasil

\begin{abstract}
Resumo: O presente trabalho busca apresentar resultados da aplicação de um protótipo para tecnologia móvel a alunos da disciplina de Estatística Aplicada à Educação, do curso de Técnico em Secretaria Escolar do Profuncionário pela Rede Estadual do Paraná; verificar se o aplicativo foi efetivo na aprendizagem dos conteúdos e conhecer a opinião dos alunos sobre o uso do protótipo na aprendizagem escolar. Para a realização do estudo foram utilizados os tipos de pesquisa bibliográfica, de campo e análise de conteúdo e os resultados mostraram que a utilização do aplicativo por alunos adultos e trabalhadores foi bem-sucedida e trouxe subsídios para proposições em outras organizações e modalidades da Educação Básica.
\end{abstract}

Palavras-chave: Ensino técnico. Mobile learning. Aplicativo.

\begin{abstract}
This paper aims to present results from the application of a mobile technology prototype to students for the subject Statistics Applied to Education, in a Profuncionário Technical Teaching class, in Parana State Educational System; verify the effectiveness of the application in the content learning as well as to know the students' point of view about the use of the prototype in school learning. For the study, the types of bibliographic research and content analysis were used, and the results showed that the use of the application by adult students and workers was successful and brought subsidies for propositions in other organizations and modalities of Basic Education.
\end{abstract}

Keywords: Technical learning. Mobile learning. application. 
Resumen: El presente trabajo busca presentar resultados de la aplicación de un prototipo de tecnología móvil a estudiantes de la disciplina de Estadística Aplicada a la Educación, del curso de Técnico en la Escuela Secretaría del Profuncionário por la Red del Estado de Paraná; verificar si la aplicación fue efectiva en el aprendizaje de los contenidos y conocer la opinión de los estudiantes sobre el uso del prototipo en el aprendizaje escolar. Para la realización del estudio se utilizaron los tipos de investigación bibliográfica, análisis de campo y de contenido y los resultados mostraron que el uso de la aplicación por parte de estudiantes y trabajadores adultos fue exitoso y trajo subsidios a propuestas en otras organizaciones y modalidades de Educación Básica.

Palabras clave: Aprendizaje técnico. Aprendizaje móvil. Aplicación.

\section{Introdução}

Com a finalidade de atingir os objetivos da Educação Técnica há a necessidade do estabelecimento de estratégias metodológicas que foquem na construção das condições mínimas do aluno realizar suas atividades profissionais, por vezes em um espaço de tempo e organização curricular diferentes do padrão da Educação Básica. A reorganização da oferta da Educação Profissional na educação pública, em meados da primeira década deste século, possibilitou que uma gama ampla de áreas fosse organizada no Catálogo Nacional de Cursos Técnicos - CNCT.

A legislação atual possibilita que os cursos técnicos sejam ofertados em três organizações possíveis: integrado, concomitante ou subsequente ao Ensino Médio. O curso técnico integrado e subsequente quase na sua totalidade é ofertado pelas redes estaduais de ensino e pela Rede Federal de Educação Tecnológica. Já a oferta do técnico concomitante é majoritária no Serviço Nacional da Indústria - SESI, onde o Ensino Médio e Ensino Técnico em turnos distintos.

Dentre os 13 eixos tecnológicos presentes no CNCT, o eixo Desenvolvimento Educacional e Social procurou reunir os cursos voltados às tecnologias relacionadas a atividades sociais e educativas, tendo como público os funcionários das escolas, especialmente o das instituições públicas, conforme a Lei 12.014/2009, a qual oficializa os egressos dos cursos deste eixo na ativa como educadores. A demanda trazida pela necessidade de atender a legislação, aliada à necessidade de oferta de uma formação em serviço, possibilitou uma configuração curricular diferenciada que abriu possibilidades de inserção de diferentes alternativas metodológicas para sua integralização.

Uma das propostas é o Programa de Formação Inicial em Serviço dos Profissionais da Educação Básica dos Sistemas de Ensino Público - PROFUNCIONÁRIO -, iniciado em 2005, 
resultado da parceria do Ministério da Educação com as redes estaduais e ultimamente com as redes municipais de ensino. Foram definidos cinco cursos técnicos para atender a comunidade administrativa escolar: Secretaria Escolar, Multimeios Didáticos, Biblioteconomia, Alimentação Escolar e Infraestrutura Escolar. Estes cursos contemplam todas as áreas do suporte necessário para o funcionamento do estabelecimento educacional. O Profuncionário é um programa federal que promove a formação técnica dos agentes educacionais em parceria com as redes estaduais e municipais, nesse caso específico a Secretaria de Educação do Paraná, fato que motiva os alunos a se referirem mais ao Programa do que ao curso.

Especificamente, no que se refere à oferta dos cursos do Profuncionário no Paraná, o foco deste estudo concentra-se em currículos com disciplinas e blocos de formação. A matriz do curso Técnico em Secretaria Escolar é composta de 21 disciplinas mensais, divididas cada um em 4 semanas, sendo que durante cada semana os alunos realizam atividades presenciais e não-presenciais, além de um Prática Profissional Supervisionada, uma espécie de estágio contínuo de aplicação dos conteúdos das disciplinas, perfazendo uma organização de oferta chamada de modular subsequente, com $70 \%$ da carga horária a distância e 30\% presencial.

Preliminarmente, para cursar o Profuncionário é necessário que os alunos tenham o Ensino Médio completo e sejam agentes educacionais efetivos do estado do Paraná. Por ser um curso de 1500 horas, ou seja, com a mesma carga horária dos cursos técnicos presenciais, tornase fundamental que os mecanismos de trabalho não presencial sejam eficientes. No entanto, a Secretaria de Educação do Paraná não disponibiliza ambiente de aprendizagem, o que exige dos tutores desenvolver estratégias de trabalho de acordo com suas possibilidades. Diante disso, surgiu a proposta tratada nesse artigo.

Com base nesse contexto, o estudo busca expor considerações sobre a aplicação de um protótipo para tecnologia móvel a alunos da disciplina de Estatística Aplicada à Educação, do curso de Técnico em Secretaria Escolar do Profuncionário pela Rede Estadual do Paraná; verificar se o aplicativo foi efetivo na aprendizagem dos conteúdos e conhecer a opinião dos alunos sobre o uso do protótipo na aprendizagem escolar.

\section{Educação Profissional, Ensino Híbrido e Aprendizagem Móvel: Aproximações Possíveis}

Os cursos do Profuncionário no Paraná referem-se a uma dinâmica estruturada enquanto política de formação em serviço. Assim, o aluno é trabalhador e faz esse curso por dois motivos: atendimento à legislação e promoção na carreira. A partir do início dessa década esses cursos têm sido ofertados totalmente por meio do ensino a distância (EAD), pelos Institutos Federais, 
com foco de atendimento aos trabalhadores das redes municipais. Entretanto, a oferta para os profissionais não docentes da Rede Estadual de Educação do Paraná, como início em 2006 e término em 2019, sempre pressupôs a dualidade da educação a distância e presencial.

O curso utiliza as modalidades presencial e a distância e o professor pode utilizar para as atividades a distância a metodologia que considerar mais condizente com os alunos e proposta do curso. Diante disso, parte-se muito das possibilidades de trabalho com as turmas para estabelecer como encaminhar e mensurar os conteúdos para em cada momento.

Os materiais didáticos utilizados são livros que orientam os conteúdos a serem trabalhados nas disciplinas. De acordo com o Manual de Orientações Gerais do Profuncionário “as disciplinas não são livros, mas no Profuncionário estão expressas em livros” (SILVA et al, 2014. p. 79). Essas disciplinas possuem, em sua grande maioria, carga horária de 60 horas, constituída por 18 horas presenciais, aos sábados, ( $4 \mathrm{~h} 30$ cada um), e $42 \mathrm{~h}$ para atividades a distância.

Entretanto, a carga horária não presencial não acaba na disciplina. A Prática Profissional Supervisionada - PPS, a cada disciplina propõe uma atividade de 8 a 32 horas, que o cursista faz metade na escola em que trabalha e metade em outra escola.

\begin{abstract}
A Prática Profissional Supervisionada é concebida no Profuncionário como o momento em que o estudante se situa na redefinição do seu fazer profissional, transformando atividades rotineiras em práticas educativas intencionais. Ela promove a problematização da rotina, ou seja, põe em xeque o dia a dia do trabalho dos funcionários em seus respectivos espaços, à luz do projeto político pedagógico da escola. A PPS também se destina a criar novas possibilidades de práticas educativas na escola, com base nas disciplinas dos cursos do Profuncionário e nas necessidades educativas da escola (MONLEVADE, 2014. p. 21).
\end{abstract}

Essa atividade é utilizada para a realização de leituras, as quais são retomadas nas interações a distância e nos encontros presenciais. Há uma relação prática contínua, podendo ser considerada uma forma de estágio profissional, só que por disciplina.

O que precisa ficar claro é a centralidade da PPS na escola ou no órgão público de atuação do cursista. Uma PPS que não levasse à trans-formação das atitudes, habilidades e valores, ou seja, das competências dos futuros técnicos em educação, teria falhado em seu objetivo. Para tanto, uma atividade em ambiente externo pode ser o elemento desencadeador das mudanças, um fator de "credibilidade" de certas propostas que em um primeiro momento podem parecer utópicas ou impossíveis (MONLEVADE, 2014. p. 21).

Pelo fato dos alunos do Profuncionário apresentarem conhecimentos diferentes sobre o uso da tecnologia, mesmo se tratando do curso de Secretaria Escolar, pressupõe-se que todas as 
inovações de sistemas informatizados cheguem primeiro para integrar o sistema educacional paranaense. No entanto, muitos desses profissionais utilizam em sua prática somente o Sistema de Registro Escolar - SERE.

Tabela 1 - Matriz Curricular do Profuncionário Secretaria Escolar

\begin{tabular}{|c|c|c|c|}
\hline \multicolumn{4}{|c|}{ CURSO TÉCNICO EM SECRETARIA ESCOLAR } \\
\hline \multirow{2}{*}{\multicolumn{2}{|c|}{ COMPONENTES CURRICULARES }} & \multicolumn{2}{|c|}{ CARGA HORÁRIA } \\
\hline & & TEORIA & PPS \\
\hline \multirow{11}{*}{$\begin{array}{l}\text { Bloco I Núcleo } \\
\text { de Formação } \\
\text { Pedagógica }\end{array}$} & Orientações Gerais do ProFuncionário & $60 \mathrm{~h}$ & - \\
\hline & Fundamentos e Práticas na EaD & $30 \mathrm{~h}$ & - \\
\hline & Orientações para a Prática Profissional Supervisionada & $30 \mathrm{~h}$ & - \\
\hline & Funcionários de Escolas: cidadãos, educadores, profissionais e gestores & $60 \mathrm{~h}$ & $16 \mathrm{~h}$ \\
\hline & Educadores e Educandos: tempos históricos & $60 \mathrm{~h}$ & $16 \mathrm{~h}$ \\
\hline & Homem, pensamento e cultura: abordagem filosófica e antropológica & $60 \mathrm{~h}$ & $16 \mathrm{~h}$ \\
\hline & Relações interpessoais: abordagem psicológica & $60 \mathrm{~h}$ & $16 \mathrm{~h}$ \\
\hline & Educação, Sociedade e Trabalho: abordagem sociológica da educação & $60 \mathrm{~h}$ & $16 \mathrm{~h}$ \\
\hline & Gestão em Educação Escolar & $60 \mathrm{~h}$ & $20 \mathrm{~h}$ \\
\hline & Sub total & 480h & - \\
\hline & Prática Profissional Supervisionada - PPS & - & 100h \\
\hline \multirow{5}{*}{$\begin{array}{|lr|}\text { Bloco } & \text { II } \\
\text { Núcleo de } & \text { de } \\
\text { Formação } & \\
\text { Técnica } & \text { Geral }\end{array}$} & Informática Básica & $60 \mathrm{~h}$ & $24 \mathrm{~h}$ \\
\hline & Produção Textual na Educação Escolar & $60 \mathrm{~h}$ & $24 \mathrm{~h}$ \\
\hline & Direito Administrativo e do Trabalho & $60 \mathrm{~h}$ & $08 \mathrm{~h}$ \\
\hline & Sub total & 180h & - \\
\hline & Prática Profissional Supervisionada - PPS & - & 56h \\
\hline \multirow{13}{*}{$\begin{array}{l}\text { Bloco } \\
\text { Núcleo } \\
\text { Formação } \\
\text { Técnica } \\
\text { Específica }\end{array}$} & Trabalho Escolar e Teorias Administrativas & $60 \mathrm{~h}$ & $08 \mathrm{~h}$ \\
\hline & Atendimento ao público & $60 \mathrm{~h}$ & - \\
\hline & Gestão Democrática nos Sistemas e na Escola & $60 \mathrm{~h}$ & $24 \mathrm{~h}$ \\
\hline & Legislação Escolar & $60 \mathrm{~h}$ & $24 h$ \\
\hline & Legislação Estadual & $60 \mathrm{~h}$ & - \\
\hline & Técnicas de Redação e Arquivo & $60 \mathrm{~h}$ & $32 \mathrm{~h}$ \\
\hline & Contabilidade na Escola & $60 \mathrm{~h}$ & $16 \mathrm{~h}$ \\
\hline & Administração de Materiais & $60 \mathrm{~h}$ & $16 \mathrm{~h}$ \\
\hline & Estatística Aplicada à Educação & $60 \mathrm{~h}$ & $24 \mathrm{~h}$ \\
\hline & Sub total & $540 h$ & - \\
\hline & Prática Profissional Supervisionada - PPS & - & 144h \\
\hline & Total & 1200h & 300h \\
\hline & CARGA HORÁRIA TOTAL & \multicolumn{2}{|c|}{ 1500h } \\
\hline
\end{tabular}

Fonte: SEED-PR

Neste ínterim, enquanto curso técnico que articula a realidade do trabalhador e sua formação, as inovações propostas quanto à organização do espaço de secretaria são vinculadas à sistemas dependentes da utilização do computador enquanto extensão para resolução, armazenamento ou direcionamento de trabalho. Como nos cursos ofertados sob a responsabilidade da Secretaria de Estado da Educação do Paraná - SEED, não há proposta de 
ambiente virtual de aprendizagem, logo pôde-se pensar em estratégias de aprendizagem para o trabalho a distância.

Por conta das 3 modalidades de atividades do curso: aula presencial aos sábados, atividades a distância que contemplam a maior parte da carga horária da disciplina e a prática supervisionada que permeia todo o curso aplicando os conteúdos das disciplinas, vem à tona a necessidade de se trabalhar conteúdos de modo extrassala por meio do ensino híbrido, pela menor proporção de carga horária presencial e posteriormente associar a utilização de instrumentos inovadores como o smartphone para trabalhar os conteúdos das disciplinas.

Entende-se por ensino híbrido uma

[...] educação formal no qual um aluno aprende, pelo menos em parte, por meio do ensino online, com algum elemento de controle do estudante sobre o tempo, lugar, modo e/ou ritmo do estudo, e pelo menos em parte em uma localidade física supervisionada, fora de sua residência. Uma característica comum do ensino híbrido é que, quando um curso ocorre parcialmente online e parcialmente por meio de outras modalidades, como as lições em pequenos grupos, tutoria e etc., tais modalidades estão geralmente conectadas. Os estudantes continuam o estudo de onde pararam quando trocam de uma modalidade para outra (CHRISTENSEN, 2013, p.7).

O ensino híbrido possibilita aos estudantes, individualmente, autonomia e flexibilidade nas suas atividades e os estimula a interagir nos momentos presenciais. Assim, esta modalidade conecta diversos instrumentos voltados ao processo de aprendizagem, viabilizando a cada estudante a oportunidade de melhor aproveitamento dos momentos a distância e presenciais.

Segundo Bacich e Moran (2015), híbrido significa misturado, mesclado, blended. A educação sempre foi misturada, híbrida e combinou vários espaços, tempos, atividades, metodologias e públicos. Com a mobilidade e a conectividade, é muito mais perceptível, amplo e profundo: trata-se de um ecossistema mais aberto e criativo. $\mathrm{O}$ ensino também é híbrido porque não se reduz ao que se planeja institucionalmente, intencionalmente. Aprende-se através de processos organizados, junto com processos abertos, informais. Aprende-se quando se está com um professor e aprende-se sozinho, com colegas, com desconhecidos. Aprende-se intencionalmente e aprende-se espontaneamente.

Falar em educação híbrida significa partir do pressuposto de que não há uma única forma de aprender e, por consequência, não há uma única forma de ensinar. Existem diferentes maneiras de aprender e ensinar. O trabalho colaborativo pode estar aliado ao uso das tecnologias digitais e propiciar momentos de aprendizagem e troca que ultrapassam as barreiras da sala de aula. Aprender com os pares torna-se ainda mais significativo quando há um objetivo comum a ser alcançado pelo grupo (BACICH; MORAN, 2015). 
De acordo com Bacich et al (2015), o ensino híbrido compreende o emprego de tecnologias focadas na personalização de ações no processo ensino-aprendizagem, conectando tecnologia e currículo, interligando os momentos presenciais e não presenciais.

\begin{abstract}
Nos momentos online, em que geralmente o aluno estuda sozinho, é possível se valer do potencial das tecnologias para que o estudante tenha controle sobre seus estudos, tomando decisões que favoreçam sua autonomia. Nesse momento, é também valorizada a relação existente entre alunos, professores e tecnologia, propiciando a troca de conhecimento, a interação e o aprendizado colaborativo entre alunos e entre professores e alunos, propiciado pelas tecnologias digitais (BARION; MELLI, 2017, p. 598).
\end{abstract}

Yaegashi (2017) ecoando as palavras de Moran (2015) afirma que algumas dimensões estão ficando claras na educação formal e o modelo blended é uma delas, pelo fato de ser semipresencial, misturado, em que os alunos se reúnem de várias formas - física e digital - em grupos e momentos diferentes, de acordo com a necessidade, com muita flexibilidade, sem os horários rígidos e planejamento engessado.

Uma das alternativas para a realização da modalidade de ensino híbrido de modo a conectar recursos tecnológicos às necessidades dos alunos e aos conteúdos do currículo de um curso é a utilização do telefone celular, ou melhor, do smartphone. O uso dessa ferramenta com foco na aprendizagem é denominada de Aprendizagem móvel, em inglês, mobile learning ou m-learning. Segundo Mülbert e Pereira (2011), é o conceito que representa "a aprendizagem entregue ou suportada por meio de dispositivos de mão tais como PDA (Personal Digital Assistant), smartphones, iPods, tablets e outros pequenos dispositivos digitais que carregam ou manipulam informações". Aquilo que anteriormente se fazia de maneira fixa em um computador, conta com mobilidade acessível a ambientes educacionais semelhantes, possibilitando a otimização de atividades de aprendizagem com dispositivos móveis.

A aprendizagem móvel convoca um conjunto transdisciplinar de saberes que levam a que possa mais produtivamente ser definida, além da circunscrição formal, a partir do enunciado de variáveis, a ocorrência do fenômeno mobile learn pode ser percepcionada (e definida) como função agregada de sete grandes variáveis que se exponenciam tempo, espaço, ambiente de aprendizagem, conteúdo, tecnologias da informação, capacidades mentais do aprendente e método (VALENTIM, 2009, p. 16).

As múltiplas possibilidades dessa modalidade de aprendizagem não a tornam apenas mais flexível e facilitada, no que poderia também ser apenas precária e fragmentada, mas também amplia o leque de variáveis que podem colaborar para a aprendizagem, dando sentido e contexto ao conteúdo trabalhado. Essa linha tênue que separa o mero utilitarismo no repasse de conhecimentos e ação reflexiva no processo de aprendizagem que pode ser aprimorado pelos 
dispositivos presentes na aprendizagem móvel, pode ao invés de ampliar horizontes, encurtálos e submetê-los a uma lógica simplista.

Segundo Sobral e Passarin (2016), a aplicação de dispositivos móveis como meios didáticos pode não substituir a sala de aula, no entanto pode complementar e agregar valor aos modelos de aprendizagem existentes. A ampliação de possibilidades de ensino estendendo o aprendizado para além da sala de aula pode ser buscada pelos professores para oportunizar aos aprendizes situações personalizadas e ao mesmo tempo colaborativas. Argumenta-se que o mlearning pode proporcionar a melhoria da atuação docente, facilitando o gerenciamento de conteúdo e a interação entre alunos.

Tornou-se notória a eficiência do telefone celular enquanto tecnologia polivalente. Entretanto, a mera incorporação do instrumento tecnológico nas ações de ensino e aprendizagem não certifica seu proveito e inovação. A tecnologia, não é um fim em si mesma, mas se desvela na sua interação com os entes do processo educativo. Neste sentido, estas experiências pelas quais as pessoas passam com dispositivos móveis constroem um diferencial de modus operandi, que não pode ser somente entendido como resultado de conhecimento prático, porém pode ser fundamental para sustentar outros processos que levem os sujeitos a aprender. As experiências, diretamente, podem proporcionar mais segurança e domínio dos dispositivos móveis e aplicativos e incidem em um empoderamento em espaços digitais sociais para a aprendizagem (GARCIA, 2014, p.75).

\section{Procedimentos Metodológicos}

Os tipos de pesquisa utilizados neste estudo foram: bibliográfica, de campo e análise de conteúdo. A tipologia bibliográfica se concretiza no processo investigativo porque houve busca, seleção e uso de trabalhos e documentos publicados por estudiosos e instituições governamentais que discutem a realidade e princípios da Educação Profissional, Ensino Híbrido e Aprendizagem Móvel no contexto escolar. A pesquisa de campo ocorre uma vez que a investigação ocorreu com alunos de escolas estaduais da região central do estado do Paraná. Também de análise de conteúdo uma vez que houve reflexão sobre os resultados obtidos a partir da participação dos alunos na investigação.

Principalmente, a análise de conteúdo caracteriza-se por classificar os componentes de acordo com a verificação sobre o que ocorre em comum nestes. Essa categorização agrupa conjunto de elementos em razão de suas similaridades proporcionando, segundo Bardin (2011), que a análise de conteúdo não desencadeia equívocos, apresentando evidências consistentes 
diante dos dados qualitativos e quantitativos. Sendo assim, a categorização na análise de conteúdo é atingida enquanto procedimento de fragmentação da pesquisa em unidade para estruturar categorias, em busca de grupos de proximidade conceitual.

\subsection{Os participantes da pesquisa}

Os participantes da pesquisa são 12 funcionários de escolas estaduais, os quais atuam em diferentes setores (secretaria, biblioteca, financeira e laboratório de informática). Eles têm idade de 30 a 55 anos e cursam o Técnico em Secretaria Escolar do Profuncionário por conta de demanda profissional, tanto para avanço na carreira, quanto por atendimento à legislação. Conforme edital próprio da Secretaria de Estado da Educação do Paraná, os cursistas devem ser agentes educacionais de nível médio, sendo selecionados de acordo com o tempo de serviço e função desempenhada no estabelecimento de ensino.

\subsection{A elaboração do aplicativo}

Na busca por auxiliar no cumprimento do conteúdo da disciplina Estatística Aplicada à Educação, do curso Técnico em Secretaria Escolar do Profuncionário, foi desenvolvido o aplicativo Profuncionário. Nesse sentido, foi utilizada a plataforma Fábrica de Aplicativos (https://fabricadeaplicativos.com.br/). Esta ferramenta funciona de modo online e mediante conta paga ou gratuita, de forma muito intuitiva e simples, personalizando o seu conteúdo e layout de acordo com as necessidades de utilização. São disponibilizados templates por categoria, ou seja, classificam seus tipos de abas de acordo com a utilização. Essa criação não necessita de conhecimento prévio em linguagem de programação. O aplicativo ficou disponível a partir de 18 de maio de 2019, sendo que na semana anterior ao início da disciplina todos fizeram download do protótipo durante o momento presencial, quando também foram apresentados os ícones, as abas e os conteúdos propostos. 
Figura 1: Layout ao aplicativo Profuncionário

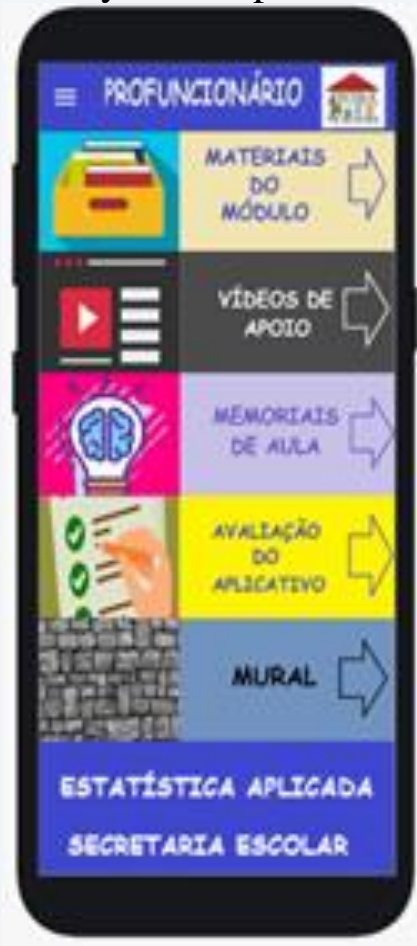

Fonte: os autores (2019)

O layout do protótipo apresenta 5 ícones centrais, os quais proporcionam mais rapidez e comodidade ao aluno para localizar o conteúdo ou a atividade. Os livros dos módulos sempre são procurados pelos alunos para referenciar as atividades, entretanto, mesmo em formato digital, ainda persistia uma dificuldade em encontrar os conteúdos semanais. Com o intuito de facilitar visualmente o acesso aos conteúdos, o primeiro ícone definido foi Materiais do Módulo, sendo composto por abas com os títulos de unidades/conteúdos da disciplina.

As demais abas do aplicativo foram determinadas de acordo com a demanda de envio de produções, comunicação com a tutoria, vídeos explicativos dos conteúdos e avaliação do aplicativo. $\mathrm{O}$ envio de produções é possibilitado pelo ícone Memoriais de Aula remete a três abas (uma para cada encontro) para que o aluno possa registrar suas impressões sobre os debates e produções dos momentos presenciais.

Por consequência, para o preenchimento e arquivo de informações foi utilizado o Formulário do Google, que é um serviço gratuito para criar formulários de forma online, pelo qual é possível produzir pesquisas de múltipla escolha, elaborar questões discursivas, solicitar avaliações em escala numérica, entre outras opções.

O ícone Mural foi estruturado para a necessidade emergencial de contato e dúvidas sobre as atividades das disciplinas, na perspectiva do estudante tem atendimento rápido da 
tutoria e que se evite que alguma falta de esclarecimento atrase o fluxo entre as atividades, bem como a dinâmica entre momentos presenciais e não presenciais.

O ícone Vídeos de Apoio teve como função estabelecer a possibilidade facilitada de acesso a vídeos selecionados sobre os temas das unidades da disciplina. Conforme mencionado anteriormente, os Institutos Federais ofertam o curso com videoaulas. Assim, foram selecionadas aulas específicas sobre os temas de Estatística, para otimização em caso de dúvidas fundamentais na execução da prática supervisionada.

O ícone Avaliação do Aplicativo, atrelado ao Formulário do Google, apresentou resultados da avaliação da experiência de utilizar o dispositivo móvel enquanto instrumento de aprendizagem. Tornou-se fundamental para que o feedback dos usuários possibilite caminhos para a reflexão sobre a utilização de aplicativos no ensino.

\section{APRESENTAÇÃO E ANÁLISE DE DADOS}

Nesta seção, serão analisados os resultados da aplicação do protótipo Profuncionário a 12 alunos da disciplina Estatística Aplicada à Educação, do curso de Técnico em Secretaria Escolar do Profuncionário pela Rede Estadual do Paraná, desenvolvido para otimizar o aprendizado de conteúdos por semana. Os conteúdos abordados foram: variáveis, gráficos, distribuição de frequência e medidas de resumo. A análise será realizada por meio da avaliação da participação e desenvolvimento dos alunos em cada ícone do aplicativo. Os ícones são: Materiais do Módulo; Memoriais de Aula; Mural; Vídeos de Apoio e Avaliação do Aplicativo.

\subsection{Materiais do Módulo}

No intuito de organizar o processo de significação dos conteúdos, ao acessar esse ícone, o aluno tem contato com as unidades da disciplina (módulo), que de forma sequencial, facilita a consulta e a leitura. A anteriormente, o acesso era por um único documento, na maioria das vezes, em formato físico. Conforme Levy, a leitura digitalizada o leitor sai da passividade na estruturação do conhecimento que está adquirindo:

Pensemos inicialmente a coisa do ponto de vista do leitor. Se definirmos um hipertexto como um espaço de percurso para leituras possíveis, um texto aparece como uma leitura particular de um hipertexto. O navegador participa, portanto, da redação do texto que lê. Tudo se dá como se o autor de um hipertexto se constitui uma matriz de textos potenciais, o papel dos navegantes, sendo o de realizar alguns desses textos colocando em jogo, cada 
qual à sua maneira, a combinatória entre os nós. O hipertexto opera a virtualização do texto (LÉVY, 1999, p.59).

Tratando-se de alunos com vivência de aprendizagem por meio de livros físicos, a mudança do impresso para o digital não causou dificuldade nem estranhamento, ao contrário, deixaram de carregar consigo, cópias, impressões ou compêndios para as aulas ou atividades extra sala. Puderam, também, aliar a elaboração do relatório, ao computador ou celular, por meio do acesso ao conteúdo pelo aplicativo. Desta forma, todos puderam interagir com os conteúdos durante a semana e participar com mais propriedade dos momentos de aulas presenciais.

\subsection{Memoriais de Aula}

No ícone Memoriais de Aula, os alunos tiveram a oportunidade de registrar as discussões sob seu ponto de vista de aprendizado, como parte das devolutivas que compõem o conceito final da disciplina, juntamente com o relatório da prática supervisionada. Nas abas internas ao ícone, estão disponíveis 3 formulários que remetem ao dia do encontro presencial. A utilização do Formulário do Google possibilitou que os alunos tivessem um trabalho a menos para organizar e entregar, uma vez que ao finalizar o preenchimento era somente clicar no botão de envio.

Dentre os diversos softwares disponibilizados de maneira gratuita aos interessados, encontra-se o Formulário Google, onde é possível, entre outras coisas, "criar pesquisas ou votações, preparar testes para alunos, bem como coletar outras informações de forma simples e rápida". Este aplicativo funciona de maneira on-line ou off-line, possibilitando o acesso a partir de computadores, tablets e smartphones. Ainda, possibilita a criação, formatação, divulgação e tabulação dos dados de uma pesquisa de maneira rápida, fácil, e segura para o pesquisador (SANTOS et al, 2015, p. 5).

De acordo com Freitas e Souza Jr (2004), no memorial relatam-se as impressões pessoais sobre a aprendizagem, onde se oportuniza o registro das reflexões sobre os diferentes momentos da formação e sua relação com a prática. $\mathrm{O}$ uso do aplicativo aproximou os professores dos alunos no que se refere ao recebimento de atividades, envio de informes, o que otimizou o uso do tempo. Todos os alunos realizaram suas atividades nesse ícone e abas. 


\subsection{Mural}

O ícone mural foi criado para possibilitar comunicação e socialização de ideias entre os alunos. Contudo, pelo fato da existência de grupo de discussão em aplicativo de mensagens, sua utilidade ficou bastante reduzida, pelo fato do vínculo de interação entre os participantes do curso ser anterior e já realizado por meio de um aplicativo de troca de mensagens em grupo. Assim, nenhum participante acessou esse ícone.

\subsection{Vídeos de Apoio}

O ícone Vídeos de Apoio disponibilizou vídeos de conteúdos da disciplina. Pelo fato de ocorrerem outras ofertas de cursos similares pela Rede Federal de Educação Tecnológica, produziu-se e disponibilizou-se diversas vídeo aulas sobre os conteúdos da disciplina. Os vídeos foram sobre variáveis, tabelas e gráficos. Todos os alunos acessaram aos vídeos e quando tinham dúvidas sobre determinado conteúdo, podiam consultá-los.

O uso das videoaulas traz consigo muitas vantagens para o aluno e para o professor oferecendo ao aluno um auxílio no desenvolvimento dos conteúdos vistos em sala de aula. O aluno quando está assistindo uma videoaula pela internet, além desta aula ele pode acessar outros sites e ver outros vídeos com exemplos práticos daquele conteúdo que está sendo assistido na videoaula. Já o professor terá mais facilidade para contextualizar suas aulas, interligando os seus conteúdos com conteúdos de outras disciplinas compartilhando vídeos de outros assuntos que tenham relação com o conteúdo de sua videoaula (CANDEIAS; CARVALHO, 2016, p. 10).

Os alunos preferiram assistir primeiramente os vídeos para depois consultar conceitos específicos nos textos presentes no ícone Materiais do Módulo. No decorrer do uso do aplicativo, os alunos sugeriram que o conteúdo escrito e o vídeo poderiam estar relacionados por meio de link.

\subsection{Avaliação do Aplicativo}

Foi permitida a avaliação do aplicativo por meio de três questões submetidas aos 12 participantes da pesquisa. A primeira se refere à avaliação da interface do aplicativo; a segunda questionou se a utilização do aplicativo facilita a aprendizagem dos conteúdos e por último quais os benefícios da opção pelo aplicativo.

O gráfico 1 mostra os resultados da primeira questão. Dos 12 pesquisados, 10 responderam que a interface do aplicativo como satisfatória. Isso revela dois dados importantes 
sobre a viabilidade de sua utilização: a facilidade de compreensão da interface, considerada por 83,3\% dos participantes e a assiduidade na sua utilização e interação com os ícones.

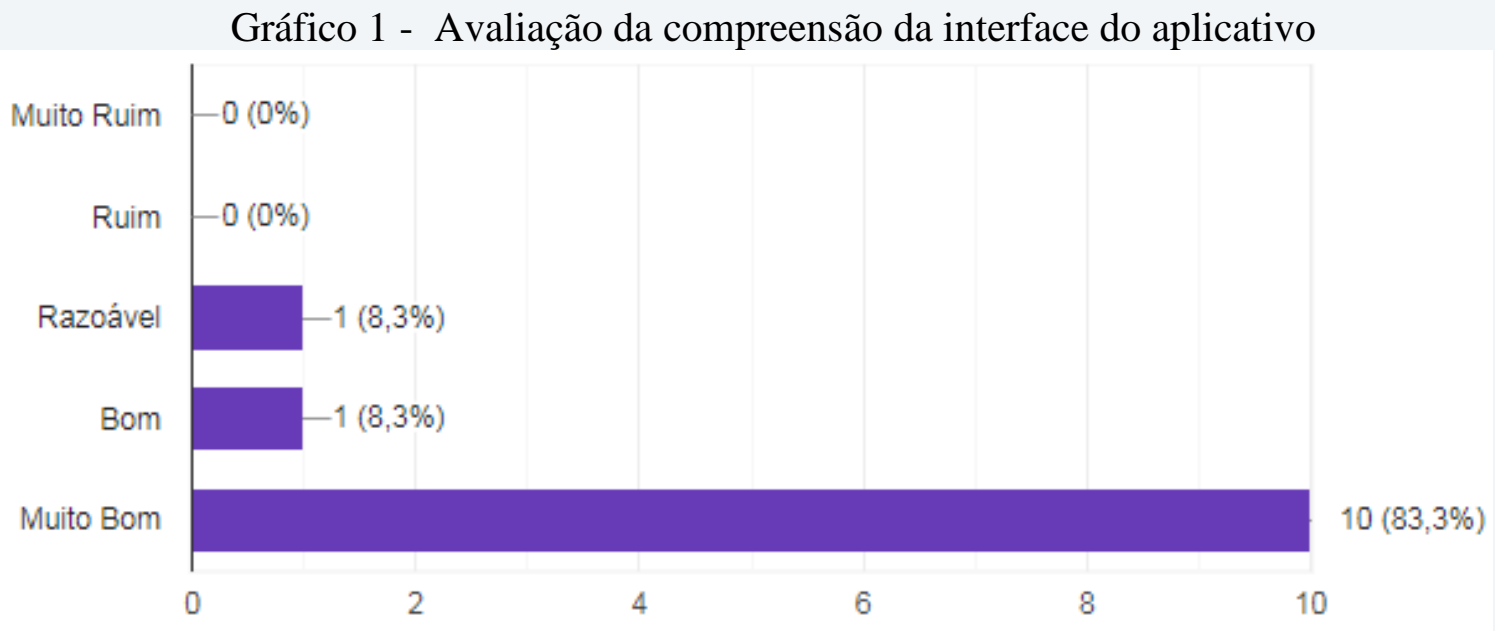

Fonte: os autores (2019)

Inicialmente, os alunos visualizaram essas tecnologias sendo inseridas na escola com certa precaução, com temor destes mecanismos sobreporem-se aos conteúdos. No entanto, conforme registros de informações no gráfico 2, sobre se a utilização do aplicativo facilita a aprendizagem dos conteúdos, $100 \%$ dos investigados relataram que a ferramenta otimizou a aprendizagem dos conteúdos e organização de ideias, o que facilitou a aprendizagem.

Gráfico 2 - Avaliação da facilidade que o aplicativo trouxe ao aprendizado da disciplina

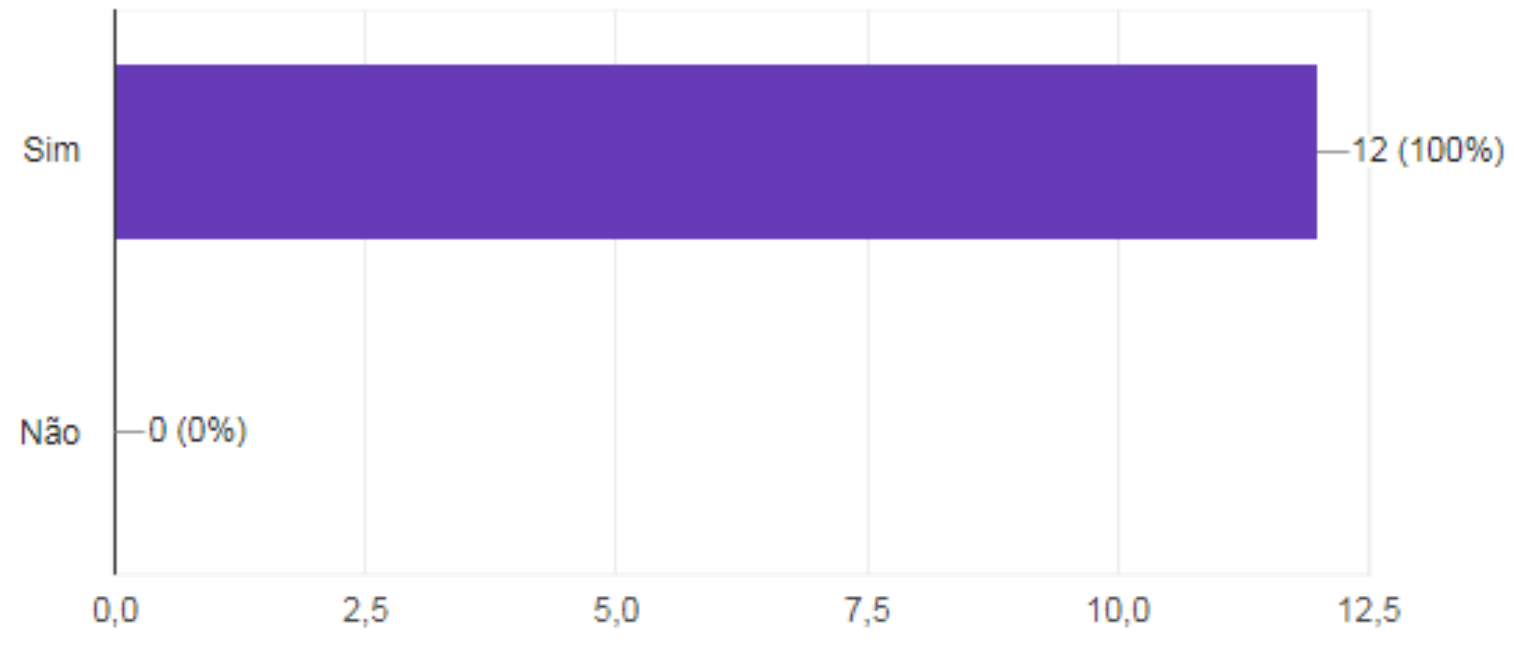

Fonte: Elaboração Própria, (2019)

A terceira questão solicitou que os alunos elenquem os benefícios da opção pelo aplicativo. Os excertos das respostas dos alunos podem também sugerir encaminhamentos para novas práticas. Para preservarmos a identidade dos cursistas, utilizaremos codinomes. 
“A praticidade. A realização das atividades e o envio imediato trás comodidade e segurança" -Lucia, 48 anos, secretária de escola.

“A realização do memorial ficou muito mais fácil” - Valdir, 40 anos, responsável pelo laboratório de informática de escola.

"Fica mais rápido e fácil fazer o memorial" - Vilson, 47 anos, responsável financeiro de escola.

"A possibilidade de interagir mesmo a distância" - Cleiton, 56 anos, agente de leitura de escola.

"Facilidade de escrever e enviar o memorial, tendo em vista a importância do celular em sala de aula" - Francisca, 44 anos, secretária de escola.

"Acesso a todo momento do conteúdo do módulo" - Vilma, 32 anos, secretária de escola.

“Ótimo para fazer o memorial” - Valdirene, 30 anos, secretária de escola.

“Ter contato com o módulo em qualquer lugar” - Maurício, 53 anos, responsável por laboratório de ciência de escola.

Como podemos verificar nos excertos de fala dos informantes, com o aprendizado móvel - mobile learning é possível aprender de qualquer lugar, como ressalta Valentim (2009), a mobilidade é um dos benefícios do mobile learning, pois o que diferencia favoravelmente este do e-learning não são aspectos tecnológicos, mas sua 'emergente portabilidade'. Reforça assim, a viabilidade da aprendizagem flexibilizada, abrindo diferentes interações com outros ambientes constitutivos da vivência do cursista.

As avaliações descritas remeteram em grande parte à otimização do procedimento de registro do memorial, que enquanto tarefa rotineira do curso, sempre demandou tempo para formatar e enviar as informações por e-mail. A possibilidade de registrá-lo no formulário e finalizar essa atividade trouxe maior comodidade e segurança. De forma semelhante, o fato dos conteúdos da disciplina estarem disponíveis em qualquer momento e lugar no celular foi ressaltado como benéfica e de incentivo à interatividade com novas possibilidades de aprendizagem.

Mesmo não sendo uma imposição à utilização do aplicativo para a integralização da última disciplina do curso, pelo fato da condução do curso ter incentivado a autonomia na aprendizagem dos conteúdos, todos os alunos participaram e o utilizaram ativamente. Diante da otimização do processo, os alunos ressaltaram que ao invés de ser aplicado apenas para uma 
disciplina do curso em caráter experimental, este poderia ter sido colocado em prática antes ou até mesmo durante todo o curso.

\section{Considerações finais}

A implementação do uso de tecnologia móvel no curso técnico do Profuncionário permitiu concluir que utilizado de forma planejada possibilita evolução nas práticas escolares, além dos seguintes benefícios: cumpre a ementa da disciplina e motiva a mudança de pensamento sobre a real efetividade das relações entre tecnologias de comunicação e educação formal.

Os 12 participantes utilizaram o aplicativo Profuncionário de modo efetivo. À princípio, eles se sentiram um pouco apreensivos e desconfiados, mas com o decorrer do uso perceberam que a ferramenta poderia auxiliá-los na aprendizagem, na organização, no cumprimento de prazos e na interação com o professor, colegas e conteúdos da disciplina.

A experiência de criação do aplicativo foi fundamental para perceber o quanto quem pensa a disciplina é protagonista no processo e os direcionamentos acertados podem desenvolver a autonomia e dinamicidade no educando. $\mathrm{O}$ acesso aos conteúdos da disciplina na palma da mão trouxe mais segurança na execução da prática supervisionada e também nas discussões sobre as funções da estatística na gestão escolar nos momentos presenciais.

Os conteúdos dos ícones possibilitaram acessar os temas de forma a otimizar os estudos não presenciais sem determinar organização sequencial de conteúdos, ou seja, os alunos acessavam os conteúdos cada qual para atender suas necessidades específicas. $\mathrm{O}$ aplicativo não centralizou totalmente as ações, pois as dúvidas e comunicações continuaram sendo resolvidas pelo aplicativo de troca de mensagens. Foi necessário reforçar a importância da utilização do aplicativo pelos estudantes.

É sugerido que outros docentes realizem esta prática em suas disciplinas, pois o exercício de visualizar sua disciplina em um dispositivo móvel pode potencializar o interesse pelo desenvolvimento de material didático digital, o que torna este profissional autônomo e criador de material, muitas vezes, autêntico. Além de perceber o interesse dos alunos que consideram a escola uma extensão de sua vida cotidiana e não algo desconectado.

Em implementação futura, conteúdos escritos e audiovisuais poderiam ser vinculados ou direcionados por link. Isso facilitaria para que em processo contínuo o estudante pudesse ter acesso a tudo o que o aplicativo pode oferecer sobre determinado tema e/ou conteúdo. 
Avaliamos que essa integração dos elementos do instrumento é satisfatória à medida que a familiaridade na utilização de tais dispositivos aumente.

\section{REFERÊNCIAS}

BACICH, Lilian; MORAN, José. Aprender e ensinar com foco na educação híbrida. Revista Pátio, no 25, junho, 2015, p. 45-47. Disponível em:

$<$ http://www.grupoa.com.br/revistapatio/artigo/11551/aprender-e-ensinar-com-foco-naeducacao-hibrida.aspx > acesso 20 de setembro de 2019.

BARDIN, Laurence. Análise de conteúdo. São Paulo: Edições 70, 2011.

BARION, Eliana Cristina Nogueira.; MELLI, Nádia Cristina de Azevedo. As Reflexões sobre o Ensino Híbrido na Educação Profissional. 2017. In: XII Workshop de PósGraduação e Pesquisa do Centro Paula Souza. São Paulo, 2017. Disponível em:

$<$ http://www.portal.cps.sp.gov.br/pos-graduacao/workshop-de-pos-graduacao-e-pesquisa/012workshop-2017/workshop/artigos/Educacao/Fundamentos_Praticas/As-reflexoes-sobre-oensino-hibrido.pdf $>$. Acesso em 25 set 2019.

CANDEIAS, Cezar Nonato Bezerra; CARVALHO, Luis Henrique Pereira de. O Uso de videoaulas como ferramenta no processo de ensino e aprendizagem em Química. $7^{\circ}$ Simpósio Internacional de Educação e Comunicação: Aracaju, 2016.

CHRISTENSEN, Clayton M., HORN, Michael B., STAKER, Heather.. Ensino Híbrido: uma Inovação Disruptiva? Uma introdução à teoria dos híbridos. Clayton Christensen Institute, 2013. Disponível em: https://www.pucpr.br/wp-content/uploads/2017/10/ensinohibrido_uma-inovacao-disruptiva.pdf Acesso em: 19 ago. 2019

FREITAS, Dayse Stefanie de Lima; SOUZA JR, Arlindo José de. Importância do memorial enquanto estratégia de formação profissional no projeto veredas. Uberlândia: Revista Olhares e Trilhas, v.5, n.1 (Jan./Dez. 2004)

GARCIA, Marilene. Mobile-Learning: do acesso, às oportunidades de aprendizagem. Rio de Janeiro: Revista Tecnologia Educacional (jul/set. 2014).

LÉVY, Pierre. Cibercultura. São Paulo: Ed. 34, 1999

MONLEVADE, João Antonio Cabral de; Orientação para a Prática Profissional Supervisionada. Cuiabá: Universidade Federal de Mato Grosso / Rede e-Tec Brasil, 2014.

MÜLBERT, Ana Luisa; PEREIRA, Alice. T. Cybis. Um panorama da pesquisa sobre aprendizagem móvel (m-learning). In: Associação Brasileira de Pesquisadores em Cibercultura, 2011, Florianópolis. Anais do V Simpósio Nacional da ABCiber. Disponível em: 〈http://abciber.org.br/simposio2011/anais/Trabalhos/artigos/Eixo\%201/7.E1/80.pdf〉. Acesso em 19 jul. 2019.

SANTOS, Leandro Dorneles; POLACINSKI, Edio; GODOY, Leoni Pentiado; GESSI, Nedisson Luis; PATIAS, Jovani. O uso de recursos digitais para auto avaliação do 
trabalho docente: um estudo de caso na administração. Congresso Internacional de Administração 2015. Ponta Grossa. Disponível em:

http://www.admpg.com.br/2015/down.php?id=1513\&q=1. Acesso em 01 set 2019.

SILVA, Maria Abádia da; KIPNIS, Bernardo; BESSA, Dante Diniz; MONLEVADE, João Antonio Cabral de; NASCIMENTO, Francisco das Chagas Firmino do; Orientações Gerais. L4. ed. Cuiabá: Universidade Federal de Mato Grosso / Rede e-Tec Brasil, 2014.

\section{SOBRAL, R. C.; PASSARINI, P. S. Uso do M-learning para o desenvolvimento} profissional através de apps: um estudo survey com acadêmicos de Administração. Congresso Internacional de Administração 2016. Natal. Disponível em http://www.admpg.com.br/2016/down.php?id=2120\&q=1. Acesso em 13 set 2019.

VALENTIM, Hugo Duarte. Para uma compreensão do Mobile Learning: Reflexão sobre a utilidade das tecnologias móveis na aprendizagem informal e para a construção de ambientes pessoais de aprendizagem, 2009. Disponível em: < http://run.unl.pt/bitstream/10362/3123/1/Hugo_Valentim_M-Learning.pdf> run.unl.pt/bitstream/10362/3123/1/Hugo_Valentim_M-Learning.pdf Acesso em 15 set 2011.

YAEGASHI, Solange Franci Raimundo (Org.). Novas Tecnologias Digitais: Reflexões sobre mediação, aprendizagem e desenvolvimento. Curitiba: CRV, 2017, p.23-35.

\section{SOBRE OS AUTORES:}

\section{Belmiro Marcos Beloni}

Doutorando no Programa de Pós-Graduação em Ensino de Ciência e Tecnologia da Universidade Tecnológica Federal do Paraná, Campus Ponta Grossa, UTFPR; Mestre em Geografia, UNICENTRO; Técnico em Assuntos Educacionais na Universidade Tecnológica Federal do Paraná, Campus Guarapuava e Professor Pedagogo na Secretaria de Estado da Educação do Paraná. E-mail: belmiro@utfpr.edu.br

(iD http://orcid.org/0000-0001-7120-8798

\section{Alessandra Dutra}

Doutora em Linguística e Língua Portuguesa pela UNESP, Campus Araraquara; Professora da Universidade Tecnológica Federal do Paraná, Campus Londrina e nos Programas de PósGraduação em Ensino de Ciências Humanas, Sociais e da Natureza (Mestrado) e de Ensino de Ciência e Tecnologia (Doutorado). É bolsista de produtividade em pesquisa pela Fundação Araucária. E-mail: alessandradutra@utfpr.edu.br

(iD http://orcid.org/0000-0001-5119-3752

\section{André Luis Trevisan}

Doutor em Ensino de Ciências e Educação Matemática pela Universidade Estadual de Londrina; Professor da Universidade Tecnológica Federal do Paraná, Campus Londrina e no Programa de Pós-Graduação em Ensino de Ciências Humanas, Sociais e da Natureza (Mestrado) e de Ensino de Ciência e Tecnologia (Doutorado). E-mail: andrelt@utfpr.edu.br

(iD http://orcid.org/0000-0001-8732-1912 